\title{
Single-Walled Carbon Nanotubes-Polyamidoamine Dendrimer Hybrids for Heterogeneous Catalysis
}

\author{
Francesco Giacalone, ${ }^{* \dagger}$ Vincenzo Campisciano, ${ }^{\dagger}$ Carla Calabrese, ${ }^{\dagger}$ Valeria La Parola, ${ }^{,}$ \\ Zois Syrgiannis, ${ }^{\S}$ Maurizio Prato, ${ }^{*}, \&, \#$ Michelangelo Gruttadauria*t
}

\section{SUPPORTING INFORMATION}

\section{Contents:}

\section{Experimental: Catalytic tests}

Figure S1. HR-TEM images of 5 at different magnifications

Figure S2. HR-TEM images of 6 at different magnifications

Figure S3. (a) HR-TEM of 6, (b) magnification of a single Pd nanoparticle, (c) fast Fourier transform (FFT) pattern of the red-squared zone, (d) autocorrelation function applied to the redsquared zone

Figure S4. XPS survey spectra of 5 and 6

Figure S5. Recycling of $6(0.1 \mathrm{~mol} \%)$ in the reaction between 4-bromobenzaldehyde and phenylboronic acid

Figure S6. High resolution XPS spectra of Pd3d region of fresh and recycled 6.

Figure S7. ${ }^{1} \mathrm{H}$ NMR of 4-carbaldehyde-1,1'-biphenyl (9a)

Figure S8. ${ }^{1} \mathrm{H}$ NMR of 3-methyl-1,1'-biphenyl (9b)

Figure S9. ${ }^{1} \mathrm{H}$ NMR of 4-carbonitrile-1,1'-biphenyl (9c)

Figure S10. ${ }^{1} \mathrm{H}$ NMR of 4-nitro-1,1'-biphenyl (9d)

Figure S11. ${ }^{1} \mathrm{H}$ NMR of 4-methoxy-1,1'-biphenyl (9e)

Figure S12. 1H NMR of 4-acetyl-1,1'-biphenyl (9f).

Figure S13. ${ }^{1} \mathrm{H}$ NMR of 4,4'-dicarboxyaldehyde-1,1'-biphenyl (9g) 
Figure S14. ${ }^{1} \mathrm{H}$ NMR of the crude of 4,4'-dicarboxyaldehyde-1,1'-biphenyl stopped after 20'

Figure S15. ${ }^{1} \mathrm{H}$ NMR of the crude of 4,4'-dicarboxyaldehyde-1,1'-biphenyl after cold filtration

Figure S16. ${ }^{1} \mathrm{H}$ NMR of the crude of 4,4'-dicarboxyaldehyde-1,1'-biphenyl after hot filtration

Figure S17. ${ }^{1} \mathrm{H}$ NMR of methyl cinnamate (11a)

Figure S18. ${ }^{1} \mathrm{H}$ NMR of (E)-methyl 3-(p-tolyl)acrylate (11b)

Figure S19. ${ }^{1} \mathrm{H}$ NMR of (E)-methyl 3-(4-acetylphenyl)acrylate (11c)

Figure S20. ${ }^{1} \mathrm{H}$ NMR of (E)-methyl 3-(4-nitrophenyl)acrylate (11d)

Figure S21. ${ }^{1}$ H NMR of (E)-methyl 3-(4-methoxyphenyl)acrylate (11e).

Figure S22. ${ }^{1} \mathrm{H}$ NMR of (E)-methyl 3-(3-bromophenyl)acrylate (11f). 


\section{Catalytic tests}

\section{- Suzuki reactions with SWCNTs-PAMAM 3.0-Pd}

The catalytic tests were performed in $3 \mathrm{~mL}$ glass vials in which aryl bromide $(0.5 \mathrm{mmol})$, phenylboronic acid $(0.55 \mathrm{mmol}), \mathrm{K}_{2} \mathrm{CO}_{3}(0.6 \mathrm{mmol})$ and the catalyst $6(0.1 \mathrm{~mol} \%, 0.5 \mathrm{mg})$ were placed. Then, distilled water $(0.6 \mathrm{~mL})$ and ethanol $(0.6 \mathrm{~mL})$ were added. The reaction mixture was sonicated for a short time and heated at $50{ }^{\circ} \mathrm{C}$ for $5 \mathrm{~h}$. Then, the reaction mixture was cooled at room temperature and the crude was purified by short column flash chromatography using petroleum ether/ethyl acetate as eluent. All products and their conversions were estimated by ${ }^{1} \mathrm{H}$ NMR analysis.

\section{- Preparation of colloidal PdNPs stabilized in the presence of PAMAM 3.0G}

A solution of PAMAM 3.0G was prepared by dissolving $30 \mathrm{mg}$ of dendrimer in $3 \mathrm{~mL}$ of distilled water. Then, a $10 \%_{\mathrm{w} / \mathrm{w}}$ tetrachloropalladate solution was prepared using $\mathrm{PdCl}_{2}(0.028 \mathrm{mmol}, 5.05$ $\mathrm{mg})$ and 20 eq. of $\mathrm{NaCl}(0.56 \mathrm{mmol}, 33 \mathrm{mg})$ in distilled water $(3 \mathrm{~mL})$. The above solution was stirred at $80{ }^{\circ} \mathrm{C}$ for 20 minutes and then allowed to cool down to room temperature. Tetrachloropalladate solution was added dropwise to the stirring PAMAM 3.0G solution. The reaction mixture was stirred at room temperature for $19 \mathrm{~h}$. Then, a solution of $\mathrm{NaBH}_{4}(8 \mathrm{eq} \mathrm{in} 3 \mathrm{~mL}$ of distilled water) was added to the stirring PAMAM-PdCl${ }_{4}{ }^{2-}$ solution. The reaction mixture was stirred at room temperature for $16 \mathrm{~h}$.

\section{- $\quad$ Suzuki reactions with PAMAM 3.0-PdNPs}

Two catalytic tests were performed in $4 \mathrm{~mL}$ glass vial in which $p$-bromobenzaldehyde (1.0 mmol), phenylboronic acid $(1.1 \mathrm{mmol}), \mathrm{K}_{2} \mathrm{CO}_{3}(1.2 \mathrm{mmol})$ and PdNPs stabilized in the presence of PAMAM dendrimer as catalyst were placed. In the first test, PAMAM 3.0-PdNPs solution $(0.3 \mathrm{~mL}$, $0.1 \mathrm{~mol} \%)$, distilled water $(0.9 \mathrm{~mL})$ and ethanol $(1.2 \mathrm{~mL})$ were added. The reaction mixture was sonicated for a short time and heated at $50{ }^{\circ} \mathrm{C}$ for $5 \mathrm{~h}$. Then, the reaction mixture was cooled at room temperature and the crude was purified by short column flash chromatography using petroleum ether/ethyl acetate as eluent. ${ }^{1} \mathrm{H}-\mathrm{NMR}$ analysis showed no conversion.

The second test was carried out in the same conditions as the previous one except for the loading of the catalyst $(1.2 \mathrm{~mL}, 0.4 \mathrm{~mol} \%)$ and the reaction time $(16 \mathrm{~h})$. The reaction mixture was allowed to cool down to room temperature and the crude was purified by short column flash chromatography using petroleum ether/ethyl acetate as eluent. ${ }^{1} \mathrm{H}-\mathrm{NMR}$ analysis showed partial coupling $(<6 \%)$.

\section{- Suzuki reaction with SWCNTs-PAMAM 3.0-PdNPs and 1-chloro-4-nitrobenzene}

In a $3 \mathrm{~mL}$ glass vial 1-chloro-4-nitrobenzene $(0.5 \mathrm{mmol})$, phenylboronic acid $(0.6 \mathrm{mmol}), \mathrm{K}_{3} \mathrm{PO}_{4}$ $(0.65 \mathrm{mmol})$ and the catalyst $6(0.2 \mathrm{~mol} \%, 1.0 \mathrm{mg})$ were placed. Then DMF $(2 \mathrm{~mL})$ was added, the reaction mixture was sonicated for a short time and heated at $140{ }^{\circ} \mathrm{C}$ for $22 \mathrm{~h}$. Then, the reaction mixture was allowed to cool down to room temperature and the crude was purified by short column flash chromatography using petroleum ether/ethyl acetate as eluent. 
- Suzuki reaction with SWCNTs-PAMAM 3.0-PdNPs under microwave irradiation

In a microwave glass tube, the appropriate amount of $p$-bromobenzaldehyde $(4.0$ or $5.0 \mathrm{mmol})$, phenylboronic acid (1.1 equiv), $\mathrm{K}_{2} \mathrm{CO}_{3}$ (1.2 equiv) and catalyst 6 (0.005 or $\left.0.002 \mathrm{~mol} \%\right)$ were placed. Then, a mixture $1: 1 \mathrm{v} / \mathrm{v} \mathrm{H}_{2} \mathrm{O} / \mathrm{EtOH}(3.2$ or $4.0 \mathrm{~mL}$ ) was added. The reaction mixture was sonicated for a short time and heated under microwave irradiation $(12 \mathrm{~W})$ at $120{ }^{\circ} \mathrm{C}$ for 5 minutes. Then, the reaction mixture was allowed to cool down to room temperature and the crude has been poured into water and extracted with diethyl ether. The organic layers were dried with $\mathrm{Na}_{2} \mathrm{SO}_{4}$ and the solvent evaporated under vacuum to afford the desired product 9a in 100\% yield (confirmed by TLC and GC-MS).

\section{- SWCNTs-PAMAM 3.0-Pd recycling tests on Suzuki reactions}

Recycling tests on Suzuki reaction were performed in a glass vial in which 4-bromobenzaldehyde (1.5 mmol), phenylboronic acid $(1.65 \mathrm{mmol}), \mathrm{K}_{2} \mathrm{CO}_{3}(1.8 \mathrm{mmol})$ and the catalyst $6(0.1 \mathrm{~mol} \%, 1.5$ $\mathrm{mg})$ were placed. Then, distilled water $(1.8 \mathrm{~mL})$ and ethanol $(1.8 \mathrm{~mL})$ were added. The reaction mixture was sonicated for a short time and heated at $50{ }^{\circ} \mathrm{C}$ for $5 \mathrm{~h}$. Then, the reaction mixture was allowed to cool down to room temperature. The catalyst was recovered by centrifugation and washed with ethyl acetate, ethyl acetate/diethyl ether and acetone/diethyl ether. Once dried, the catalyst was used for the next cycle. The crude was purified by short column flash chromatography using petroleum ether/ethyl acetate as eluent. All products and their conversions were estimated by ${ }^{1} \mathrm{H}-\mathrm{NMR}$ analysis.

\section{- Heck reactions with SWCNTs-PAMAM 2.5-Pd and SWCNTs-PAMAM 3.0-Pd}

The catalytic tests were performed in $3 \mathrm{~mL}$ glass vial in which catalyst $5(0.5 \mathrm{~mol} \%, 2.5 \mathrm{mg})$ or 6 $(0.1 \mathrm{~mol} \%, 0.5 \mathrm{mg})$, aryl iodide $(0.5 \mathrm{mmol})$, methyl acrylate $(0.75 \mathrm{mmol})$, triethylamine $(1 \mathrm{mmol})$ and $\mathrm{DMF} / \mathrm{H}_{2} \mathrm{O}(0.8 \mathrm{~mL}+0.2 \mathrm{~mL})$ were placed. The reaction mixture was sonicated for a short time and heated at $90{ }^{\circ} \mathrm{C}$. Then, the reaction mixture was allowed to cool down to room temperature and the crude was purified by short column flash chromatography using petroleum ether/ethyl acetate as eluent. All products and their conversions were estimated by ${ }^{1} \mathrm{H}-\mathrm{NMR}$ analysis.

\section{- SWCNTs-PAMAM 3.0-Pd recycling tests on Heck reactions}

Recycling tests on Heck reaction were performed in a glass vial in which catalyst $6(0.1 \mathrm{~mol} \%, 1.5$ $\mathrm{mg})$, 4-iodoanisole $(1.5 \mathrm{mmol})$, methyl acrylate $(2.25 \mathrm{mmol})$, triethylamine $(3 \mathrm{mmol})$ and $\mathrm{DMF} / \mathrm{H}_{2} \mathrm{O}(2.4 \mathrm{~mL}+0.6 \mathrm{~mL})$ were placed. The reaction mixture was sonicated for a short time and heated at $90{ }^{\circ} \mathrm{C}$. Then the reaction mixture was allowed to cool down to room temperature. The catalyst was recovered by centrifugation and washed with ethyl acetate, ethyl acetate/diethyl ether and acetone/diethyl ether. Once dried, the catalyst was used for the next cycle. The crude was purified by short column flash chromatography using petroleum ether/ethyl acetate as eluent. All products and their conversions were estimated by ${ }^{1} \mathrm{H}-\mathrm{NMR}$ analysis.

\section{- Leaching studies of SWCNTs-PAMAM 3.0-Pd in Suzuki reaction}

Three parallel reactions were carried out in three glass vials using 4-bromobenzaldehyde $(0.4$ $\mathrm{mmol})$, phenylboronic acid $(0.44 \mathrm{mmol}), \mathrm{K}_{2} \mathrm{CO}_{3}(0.48 \mathrm{mmol})$ and the catalyst $6(0.1 \mathrm{~mol} \%, 0.4 \mathrm{mg})$. 
Distilled water $(0.48 \mathrm{~mL})$ and ethanol $(0.48 \mathrm{~mL})$ were employed as solvents. The reaction mixtures were sonicated for a short time and heated at $50{ }^{\circ} \mathrm{C}$. The catalyst was filtered-off after 20 minutes in all tests. In the first one, the reaction was stopped immediately after removal of the catalyst by filtration. The second reaction was quickly filtered still hot (hot filtration) and stirred (devoid of the nanocatalyst 6) for additional $4 \mathrm{~h} 40 \mathrm{~min}$. The last reaction was allowed to cool down to room temperature prior catalyst removal and stirred for $4 \mathrm{~h} 40 \mathrm{~min}$ (cold filtration). All the crudes were purified by short column flash chromatography using petroleum ether/ethyl acetate as eluent. All products and their conversions were estimated by ${ }^{1} \mathrm{H}-\mathrm{NMR}$ analysis.

- Leaching studies of SWCNTS-PAMAM 3.0-Pd in Heck reaction

Three parallel reactions were carried out in three glass vials using iodoanisole $(0.4 \mathrm{mmol})$, methyl acrylate $(0.6 \mathrm{mmol})$, triethylamine $(0.8 \mathrm{mmol})$ and the catalyst $6(0.1 \mathrm{~mol} \%, 0.4 \mathrm{mg})$ were placed. Distilled water $(0.16 \mathrm{~mL})$ and ethanol $(0.64 \mathrm{~mL})$ were employed as solvents. The reaction mixtures were sonicated for a short time and heated at $50{ }^{\circ} \mathrm{C}$. The catalyst was filtered-off after 20 minutes in all tests. In the first one, the reaction was stopped immediately after removal of the catalyst by filtration. The second reaction was quickly filtered still hot (hot filtration) and stirred (devoid of the nanocatalyst 6) for additional $4 \mathrm{~h} 40 \mathrm{~min}$. The last reaction was allowed to cool down to room temperature prior catalyst removal and stirred for $4 \mathrm{~h} 40 \mathrm{~min}$ (cold filtration). All the crudes were purified by short column flash chromatography using petroleum ether/ethyl acetate as eluent. All products and their conversions were estimated by ${ }^{1} \mathrm{H}-\mathrm{NMR}$ analysis. 

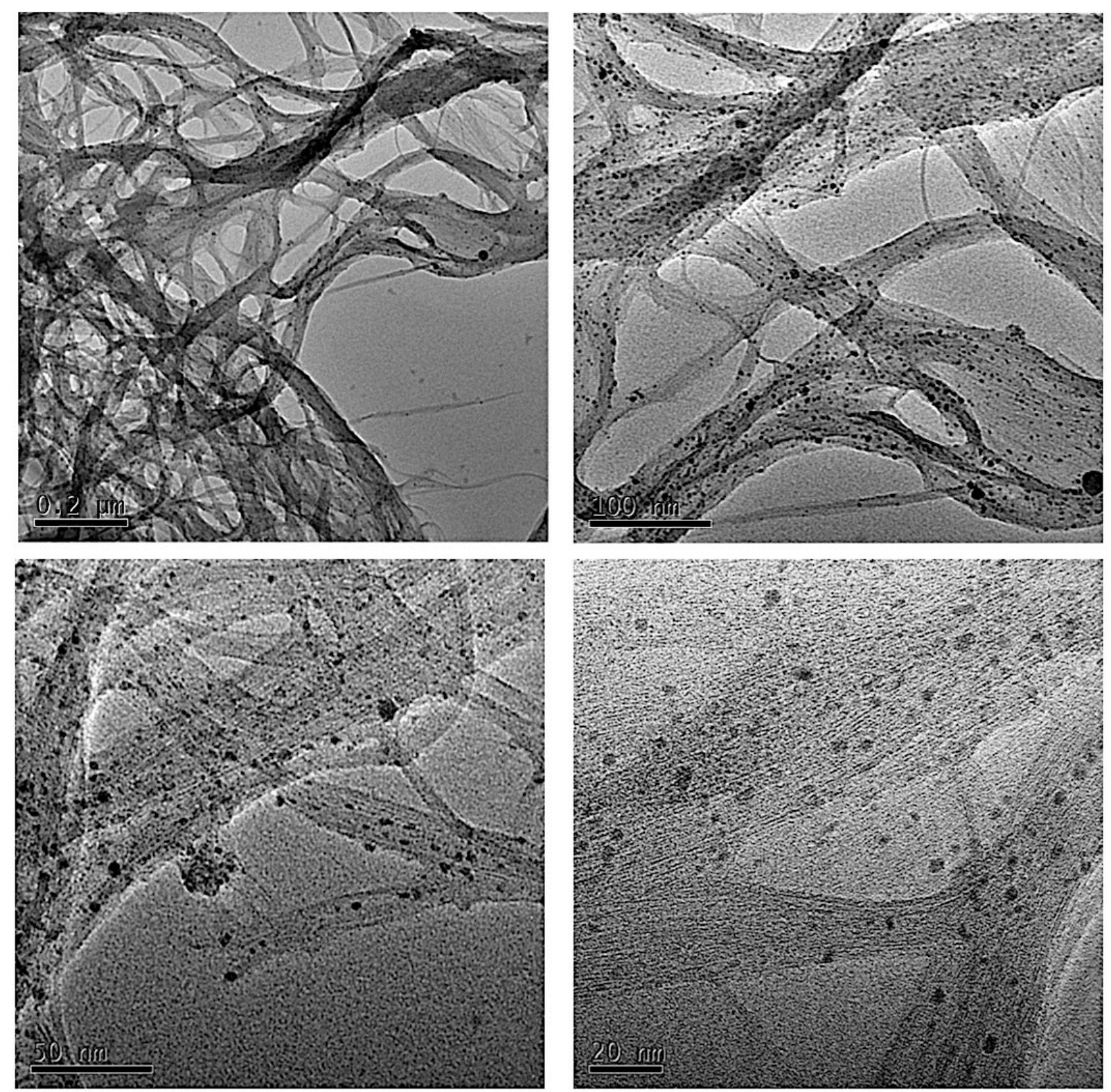

Figure S1. HR-TEM images of $\mathbf{5}$ at different magnifications. 

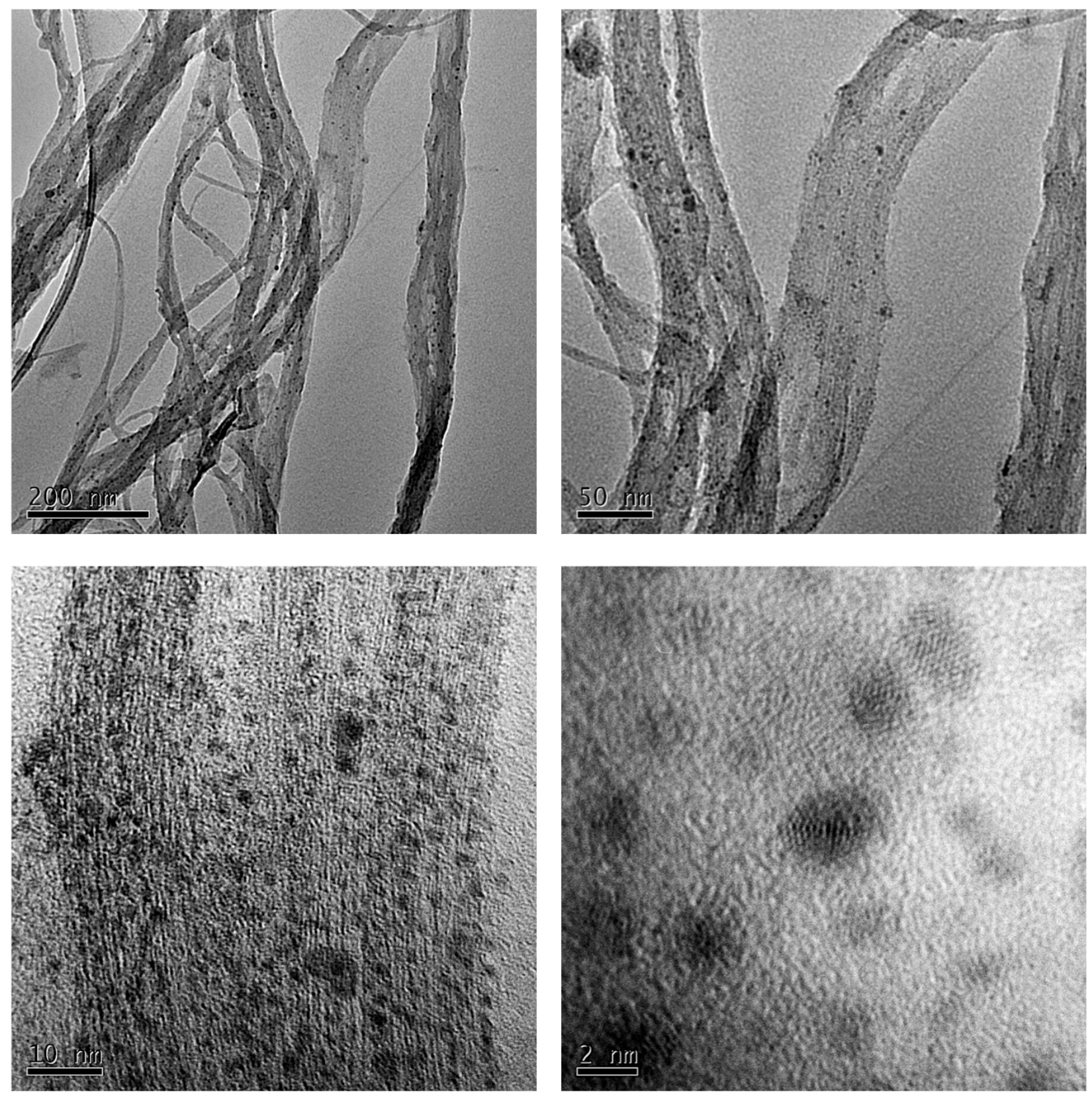

Figure S2. HR-TEM images of $\mathbf{6}$ at different magnifications. 


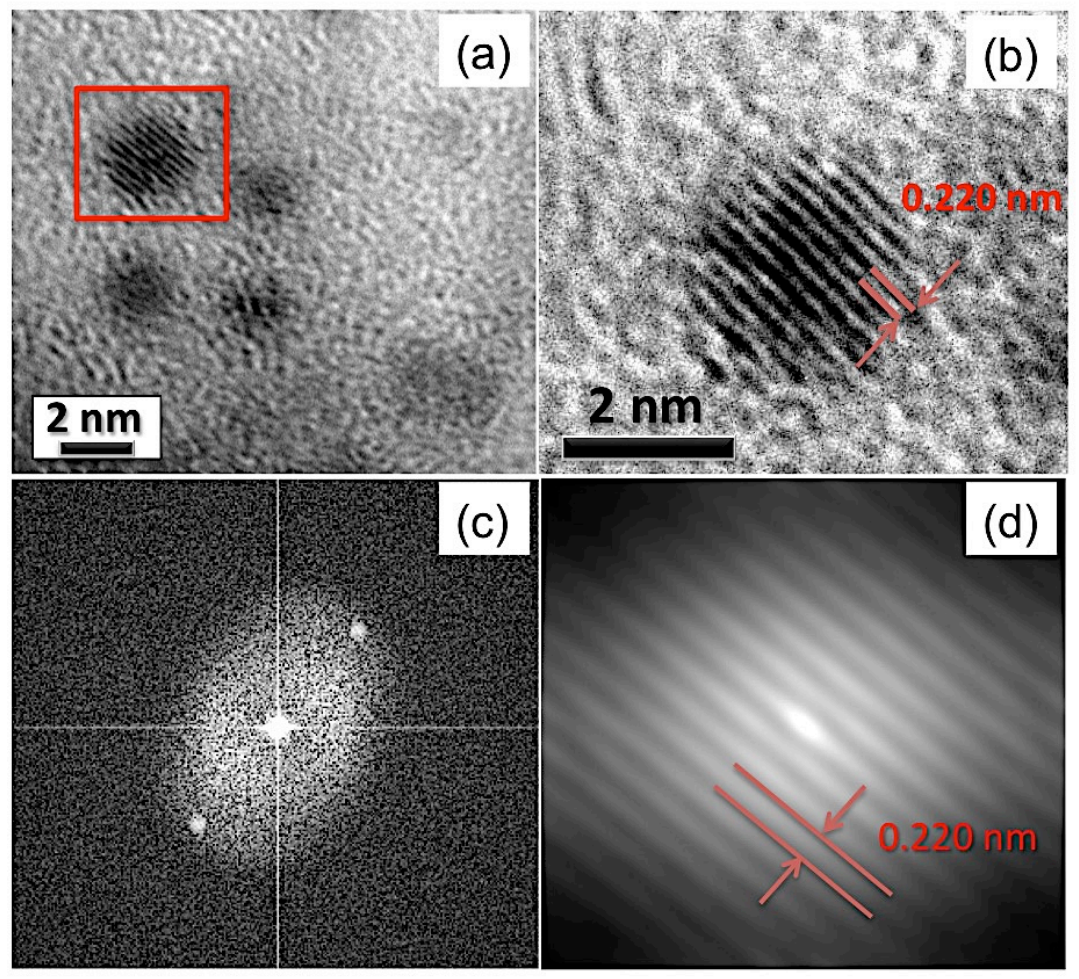

Figure S3. (a) HR-TEM of 6, (b) magnification of a single Pd nanoparticle, (c) fast Fourier transform (FFT) pattern of the red-squared zone, (d) autocorrelation function applied to the redsquared zone. 


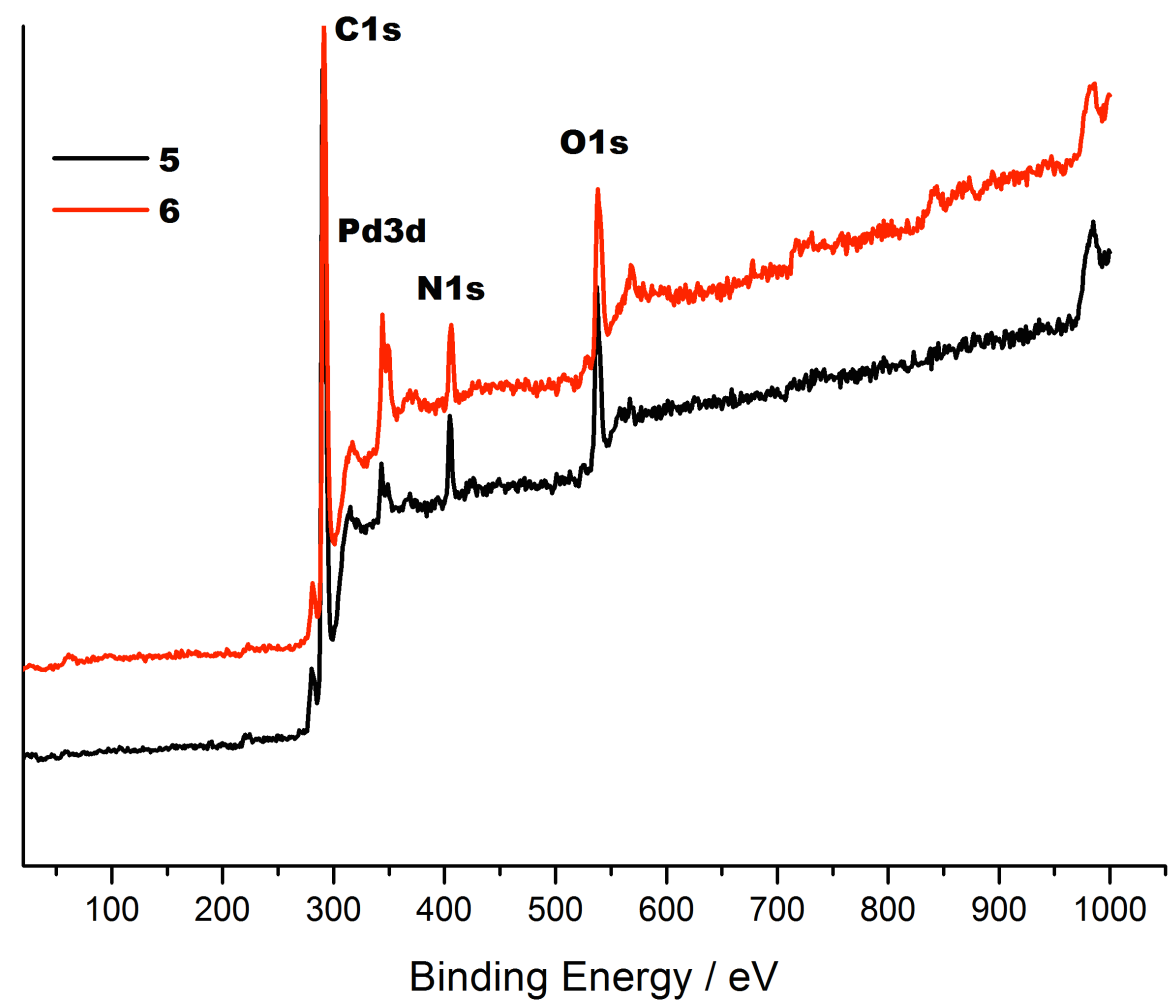

Figure S4. XPS survey spectra of 5 and $\mathbf{6}$. 


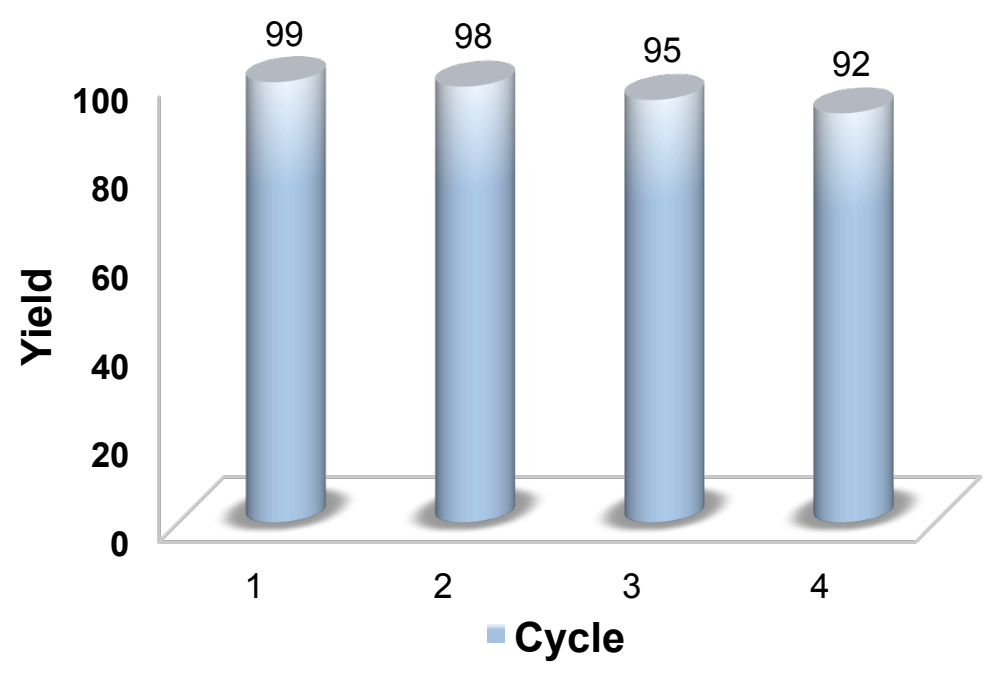

Figure S5. Recycling of $6(0.1 \mathrm{~mol} \%)$ in the reaction between 4-bromobenzaldehyde and phenylboronic acid.

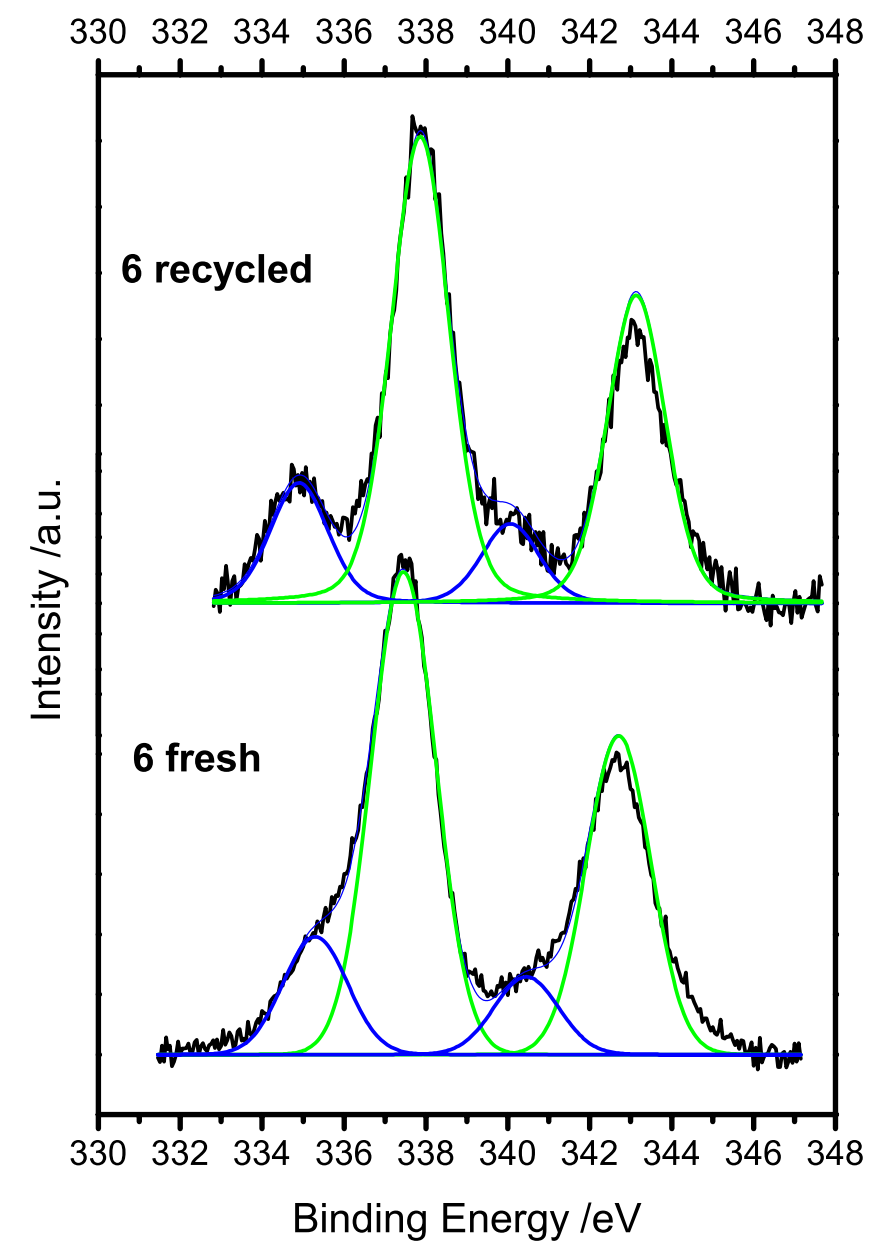

Figure S6. High resolution XPS spectra of Pd3d region of fresh and recycled 6. 


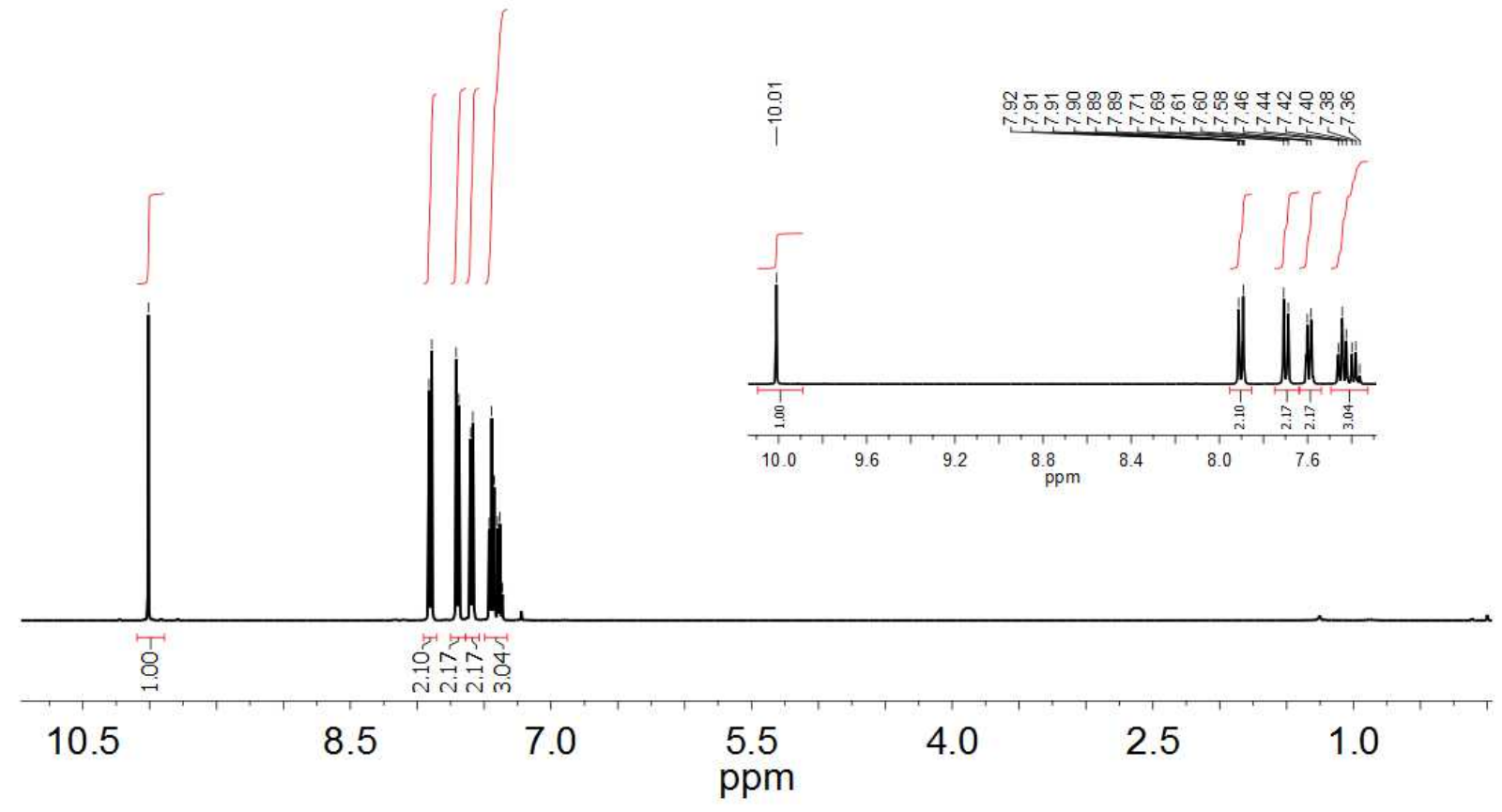

Figure S7. ${ }^{1} \mathrm{H}$ NMR of 4-carbaldehyde-1,1'-biphenyl (9a).

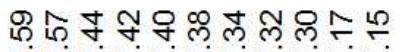

NNNNNNNNN
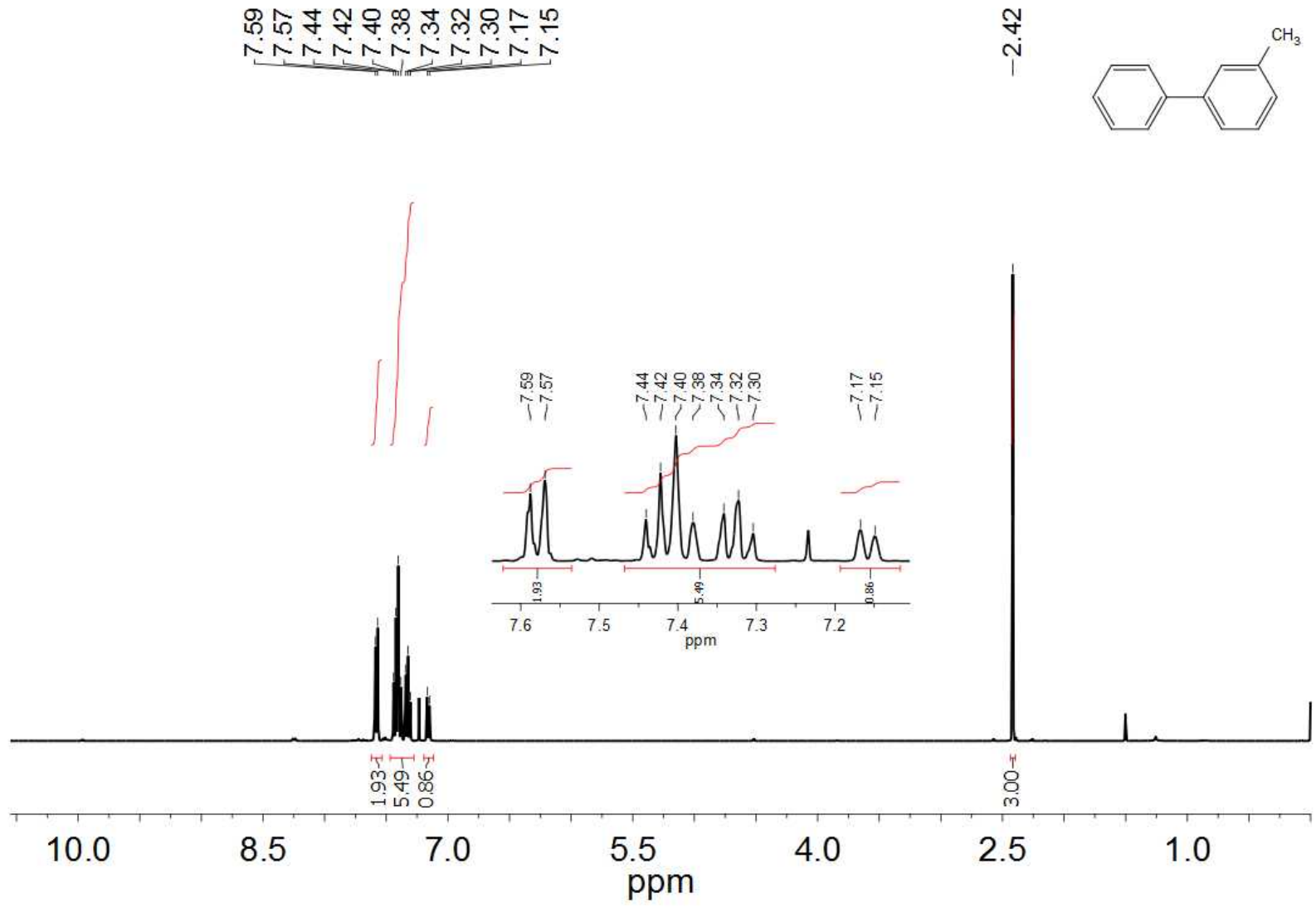

Figure S8. ${ }^{1} \mathrm{H}$ NMR of 3-methyl-1,1'-biphenyl (9b). 

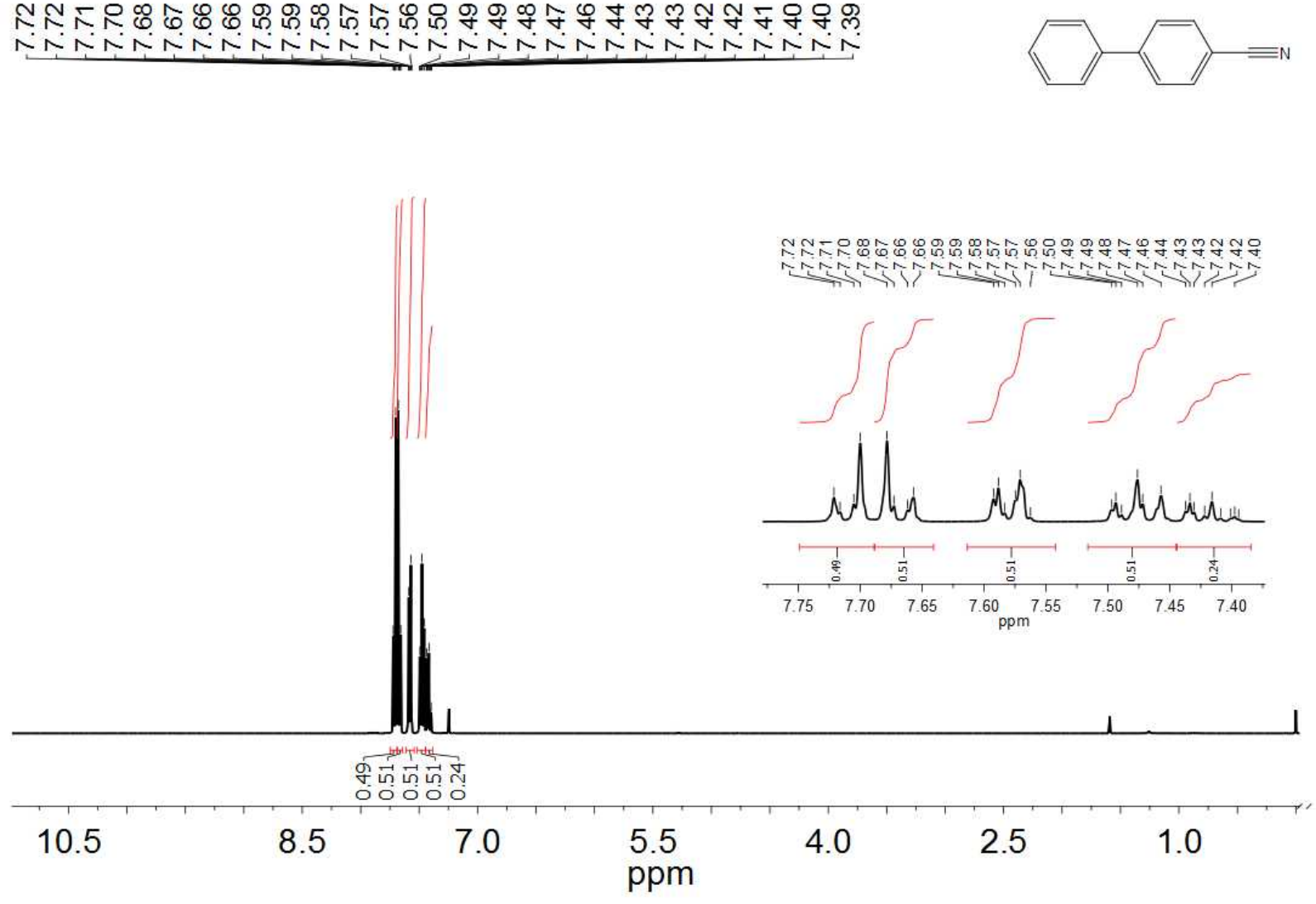

Figure S9. ${ }^{1} \mathrm{H}$ NMR of 4-carbonitrile-1,1'-biphenyl (9c).

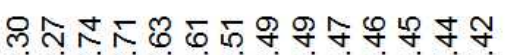

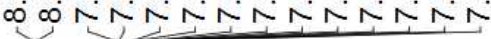
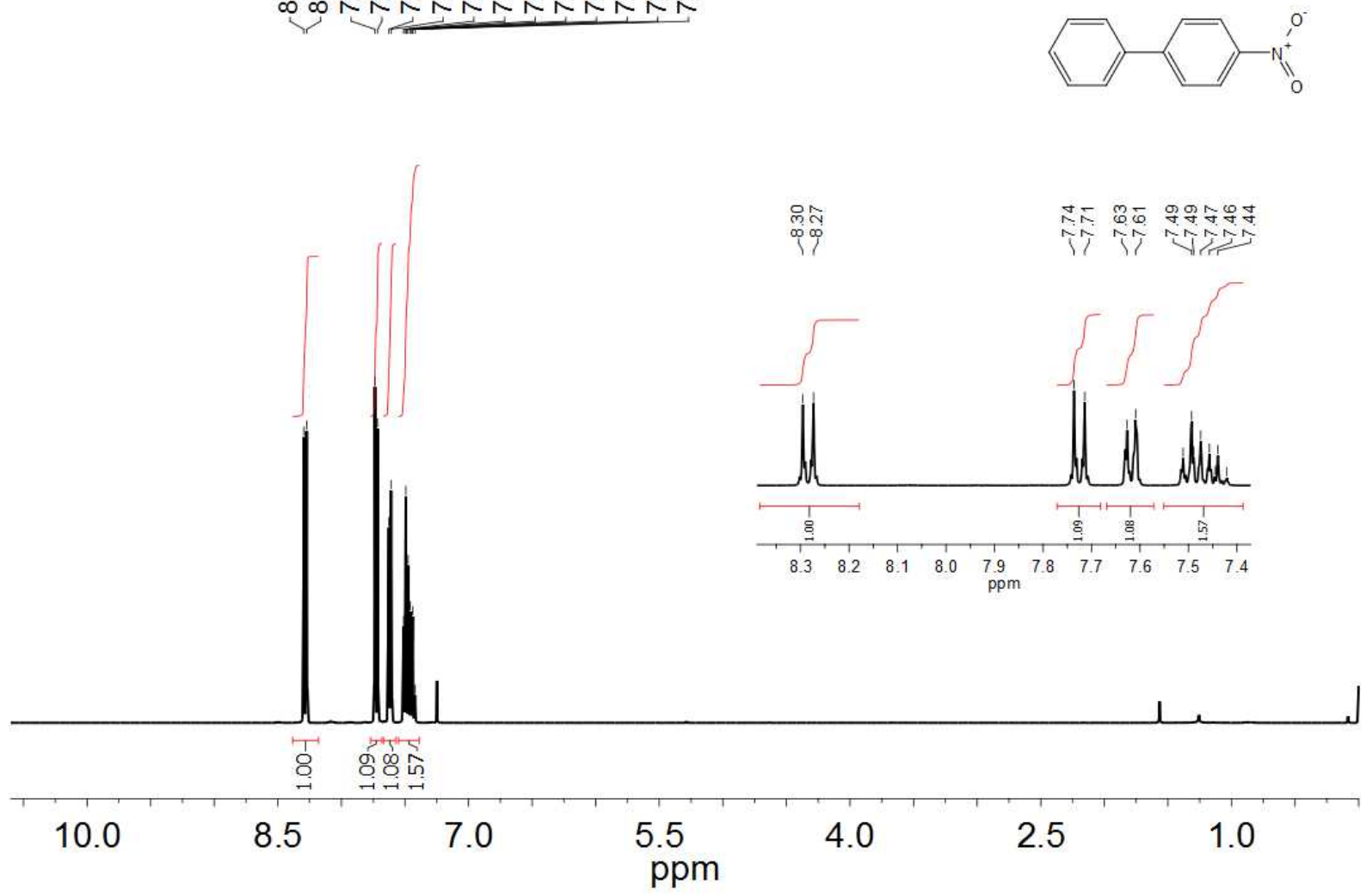

Figure S10. ${ }^{1} \mathrm{H}$ NMR of 4-nitro-1,1'-biphenyl (9d). 

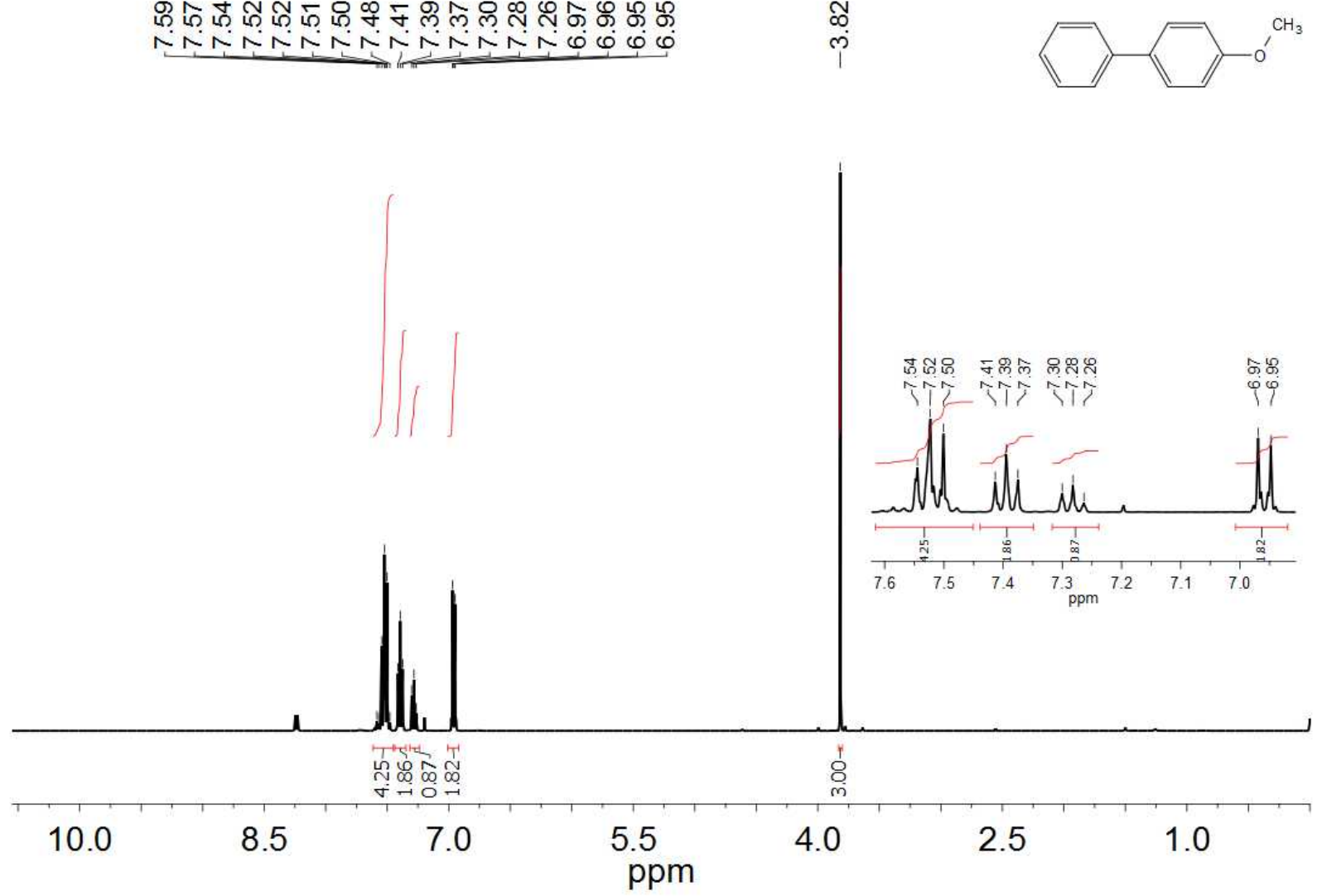

Figure S11. ${ }^{1} \mathrm{H}$ NMR of 4-methoxy-1,1'-biphenyl (9e).

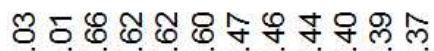

on
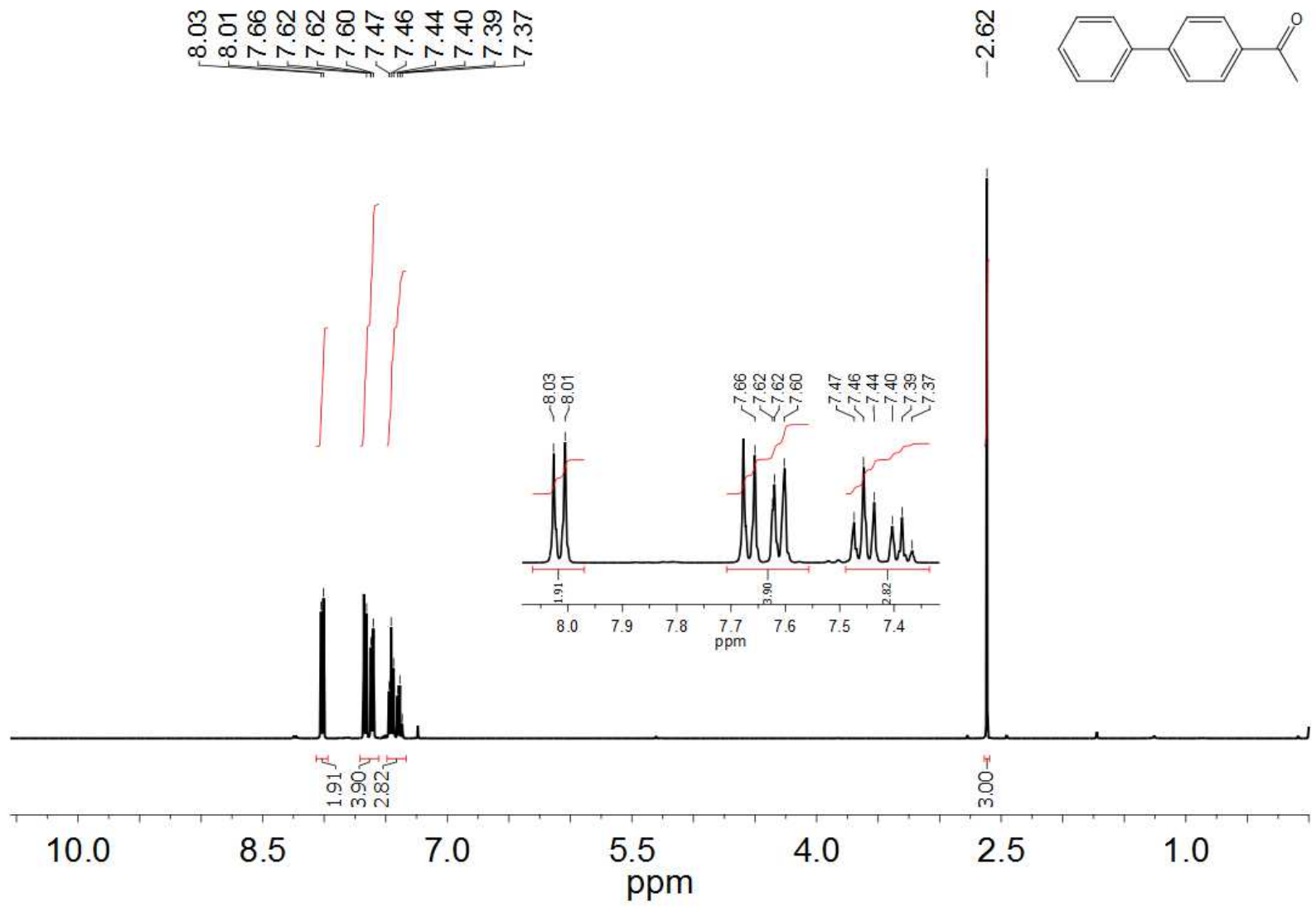

Figure S12. ${ }^{1} \mathrm{H}$ NMR of 4-acetyl-1,1'-biphenyl (9f). 

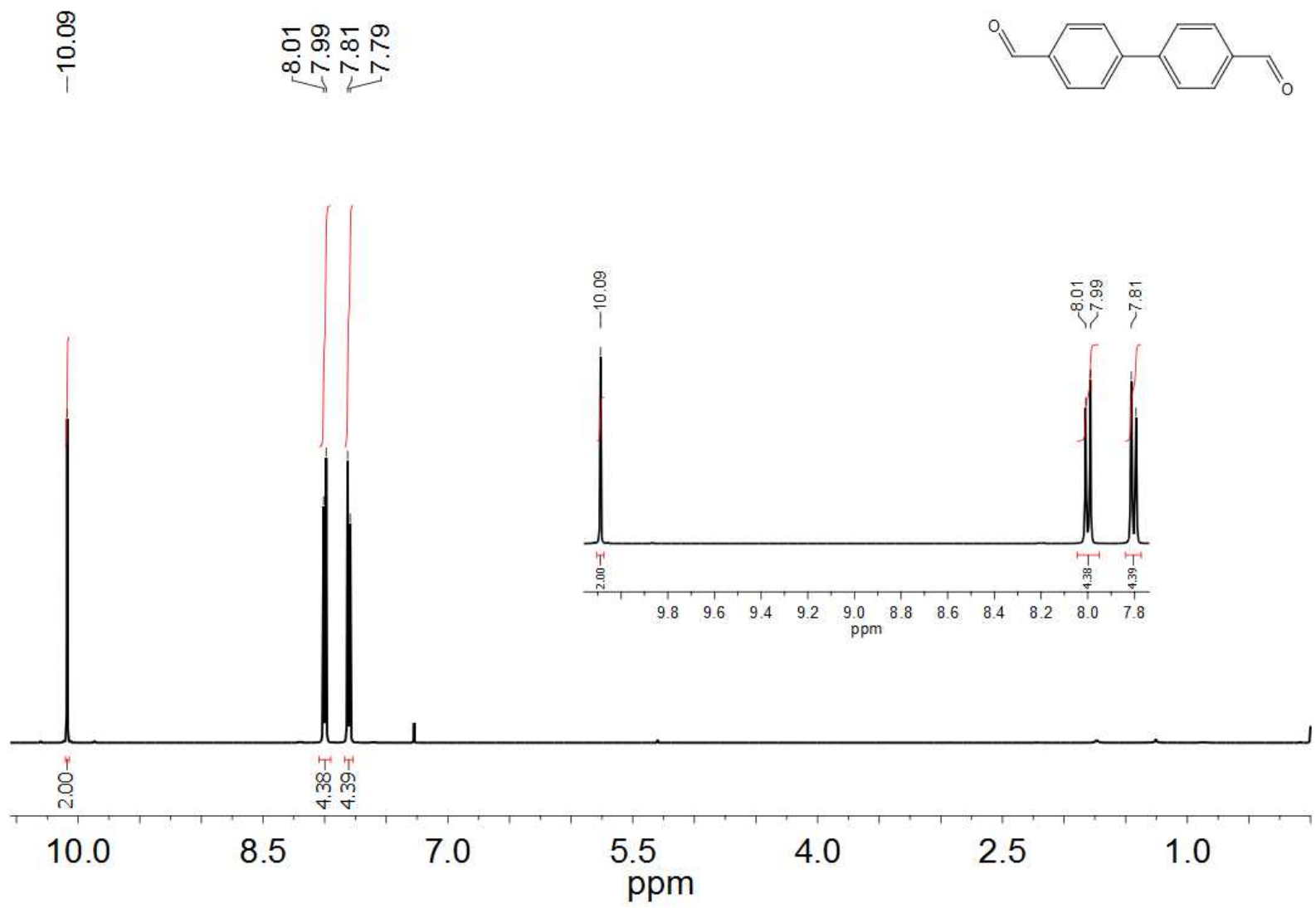

Figure S13. ${ }^{1} \mathrm{H}$ NMR of 4,4'-dicarboxyaldehyde-1,1'-biphenyl (9g). 

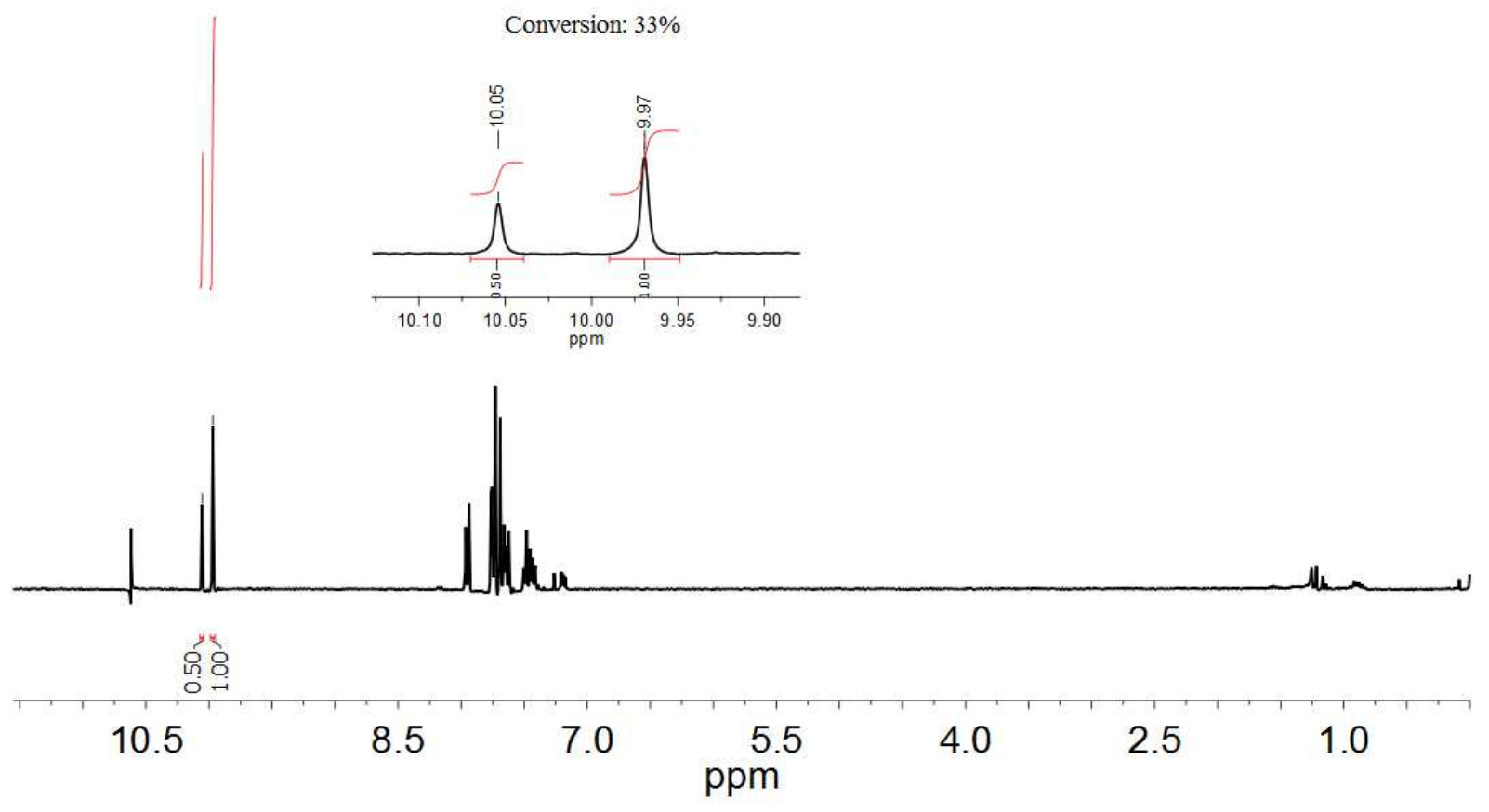

Figure S14. ${ }^{1} \mathrm{H}$ NMR of the crude of 4,4'-dicarboxyaldehyde-1,1'-biphenyl stopped after 20'.

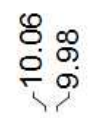

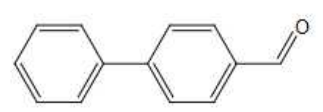

\section{Cold filtration test}
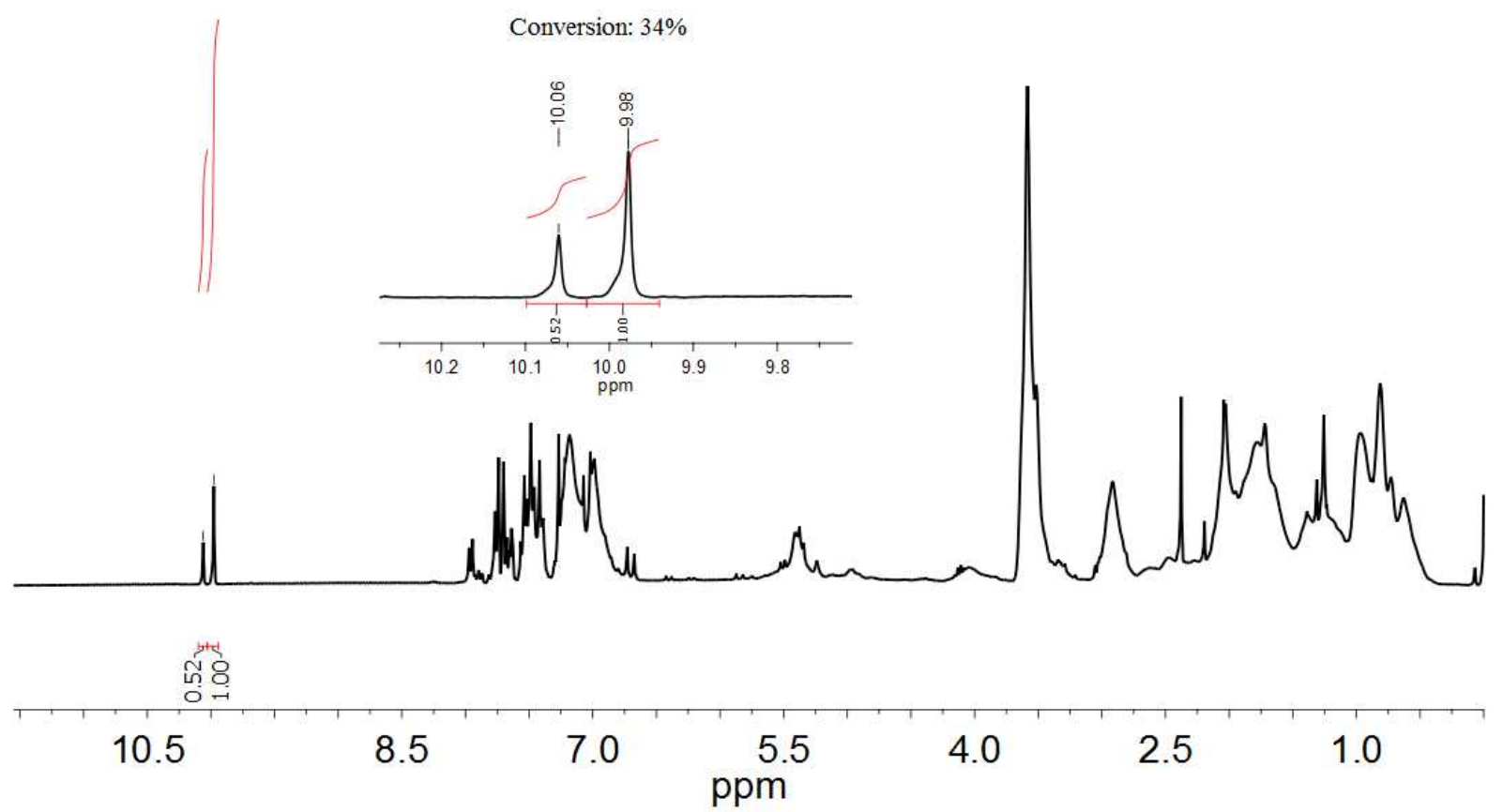

Figure S15. ${ }^{1} \mathrm{H}$ NMR of the crude of 4,4'-dicarboxyaldehyde-1,1'-biphenyl after cold filtration. 


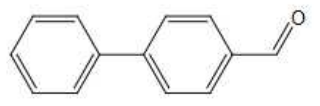

\section{Hot filtration test}
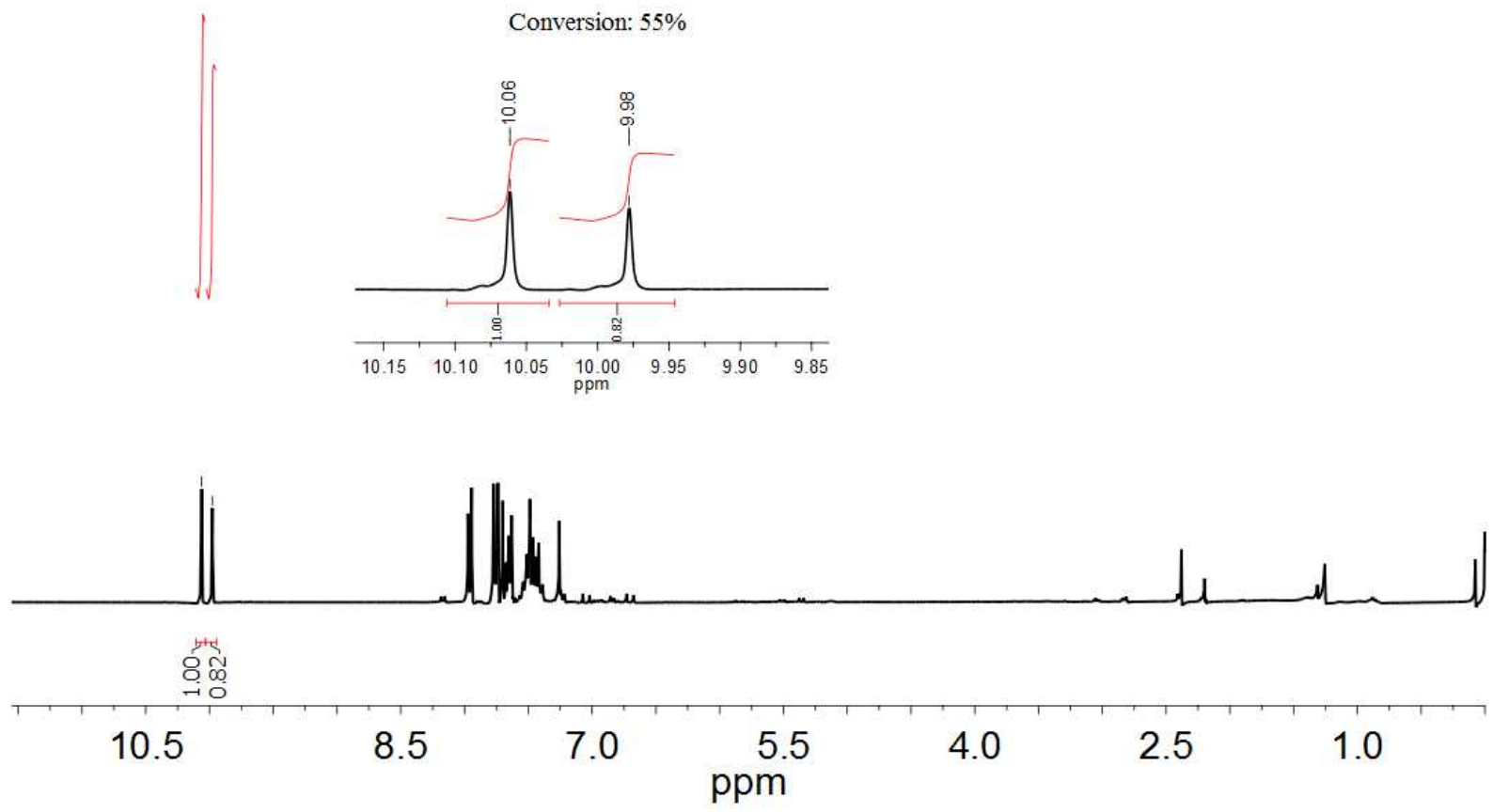

Figure S16. ${ }^{1} \mathrm{H}$ NMR of the crude of 4,4'-dicarboxyaldehyde-1,1'-biphenyl after hot filtration. 


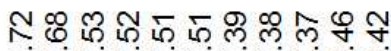

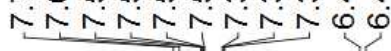

$\stackrel{\circ}{\stackrel{\circ}{1}}$
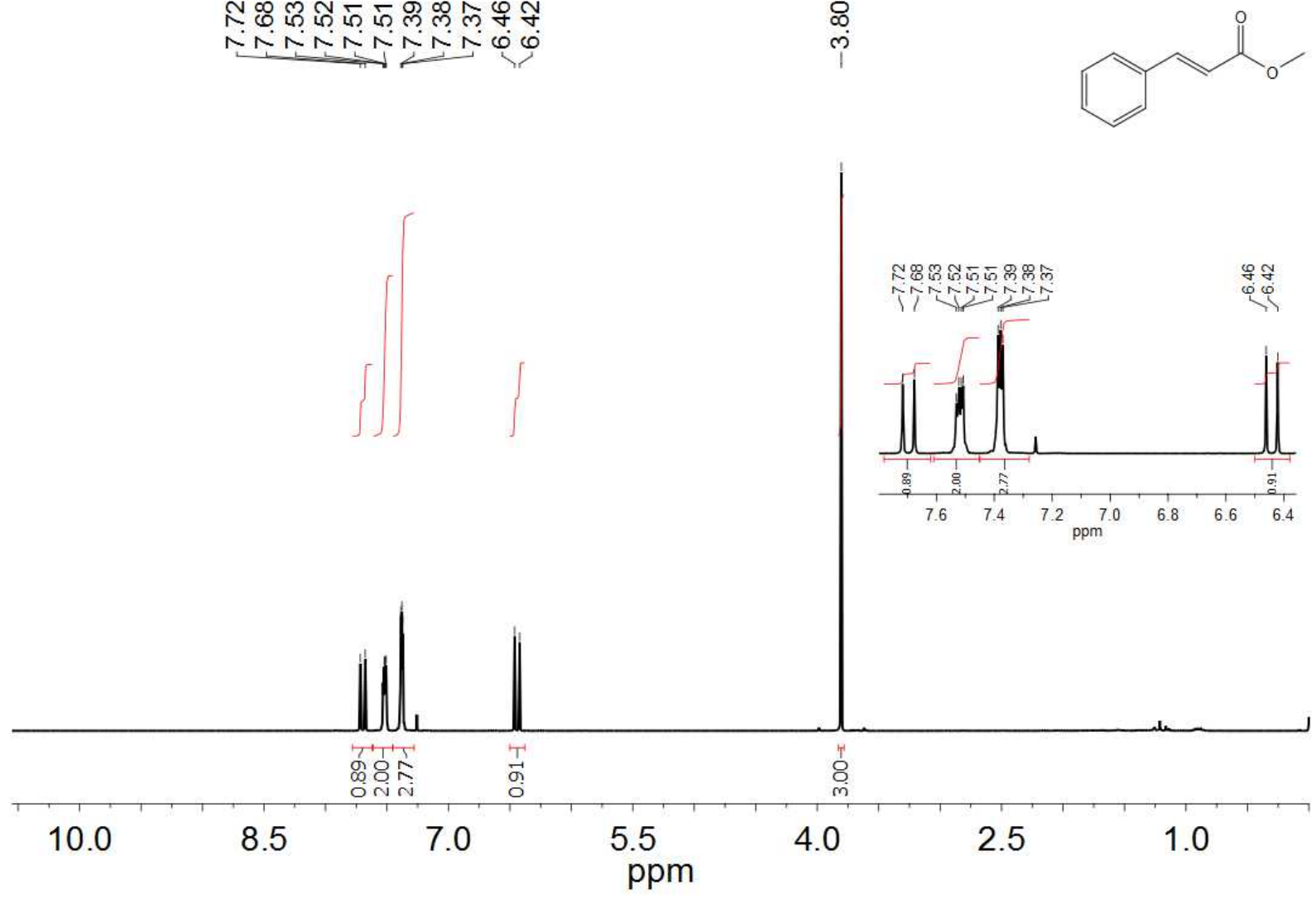

Figure S17. ${ }^{1} \mathrm{H}$ NMR of methyl cinnamate (11a).
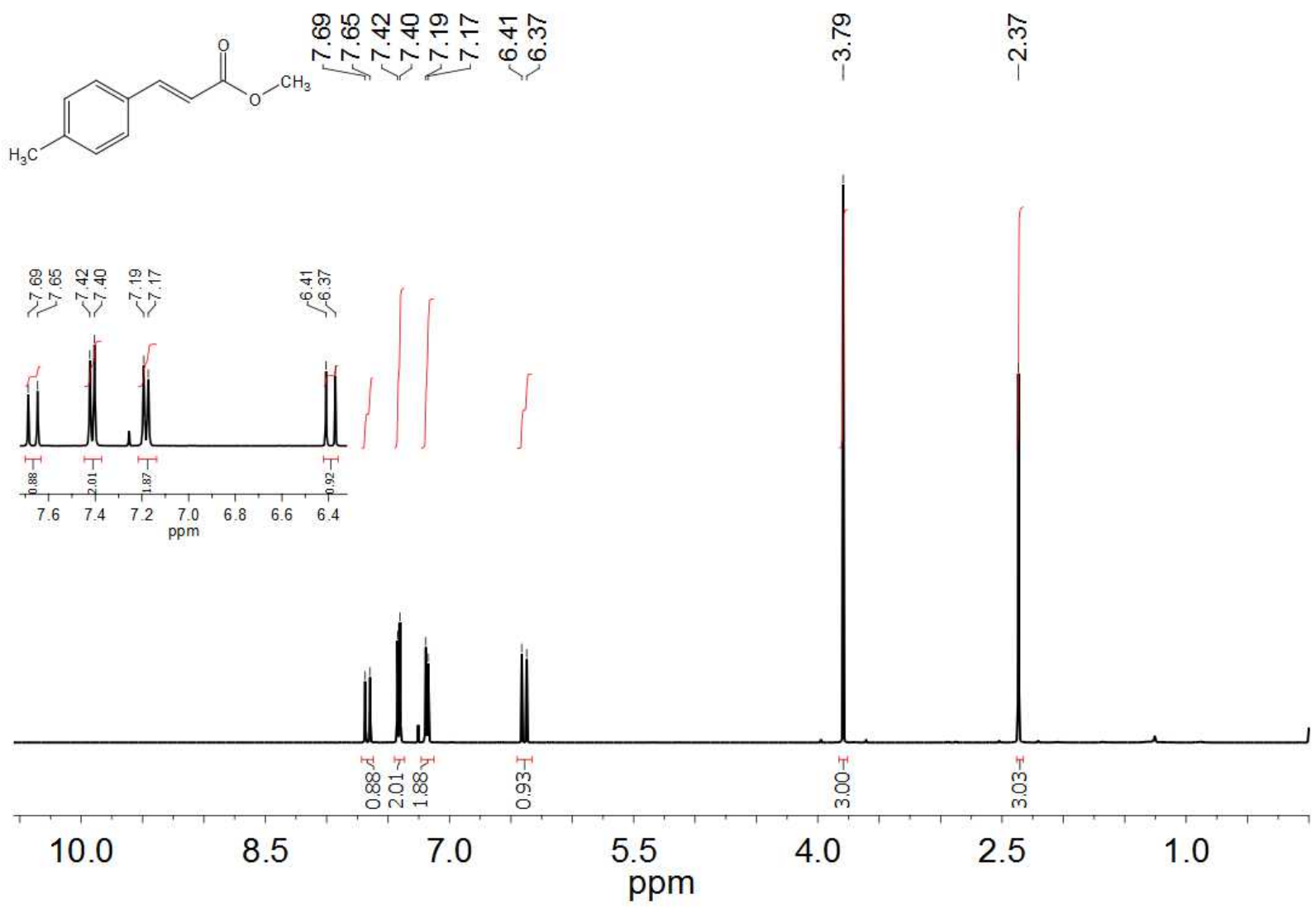

Figure S18. ${ }^{1} \mathrm{H}$ NMR of (E)-methyl 3-(p-tolyl)acrylate (11b). 


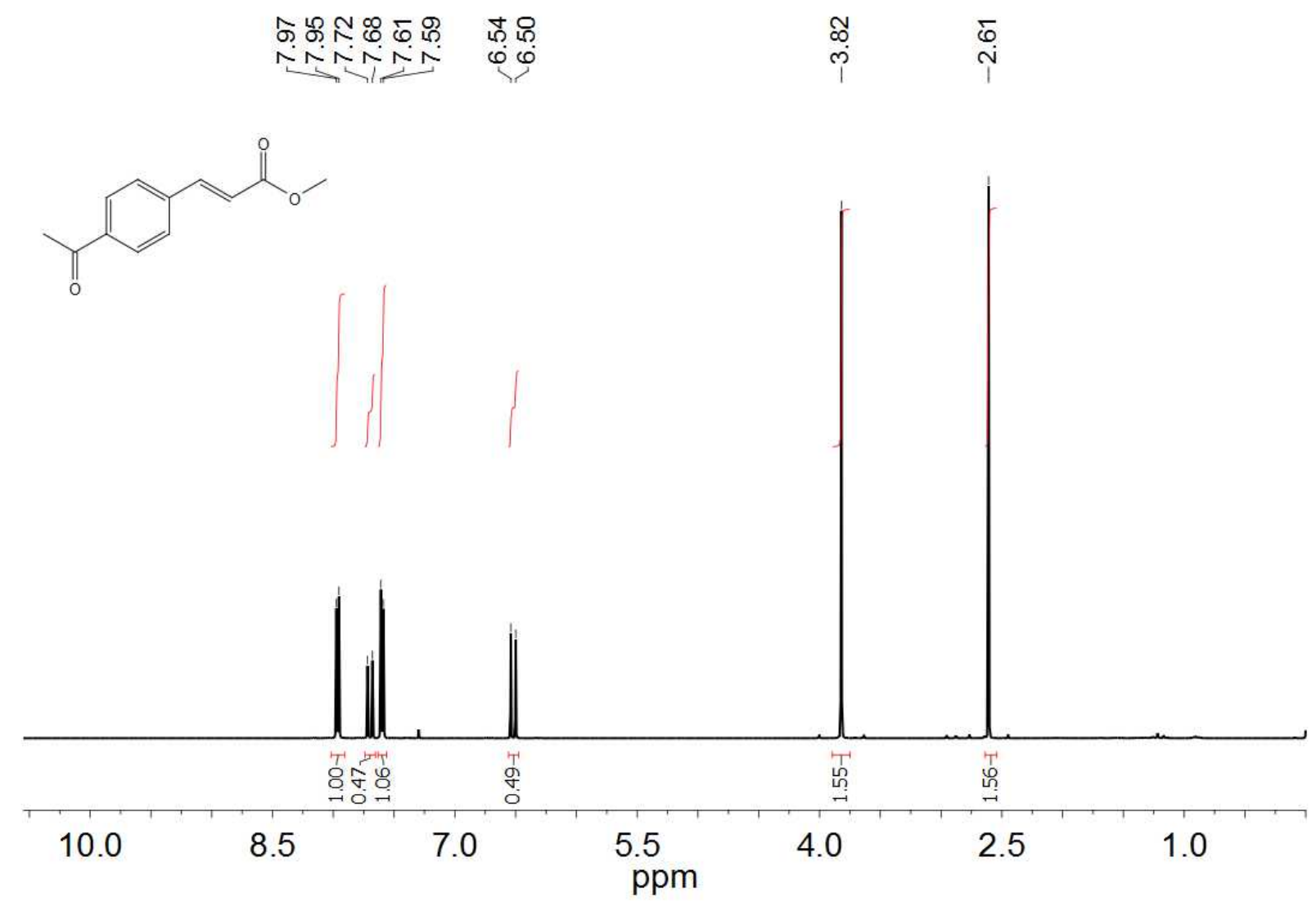

Figure S19. ${ }^{1} \mathrm{H}$ NMR of (E)-methyl 3-(4-acetylphenyl)acrylate (11c).

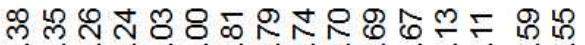

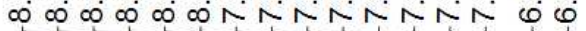

高
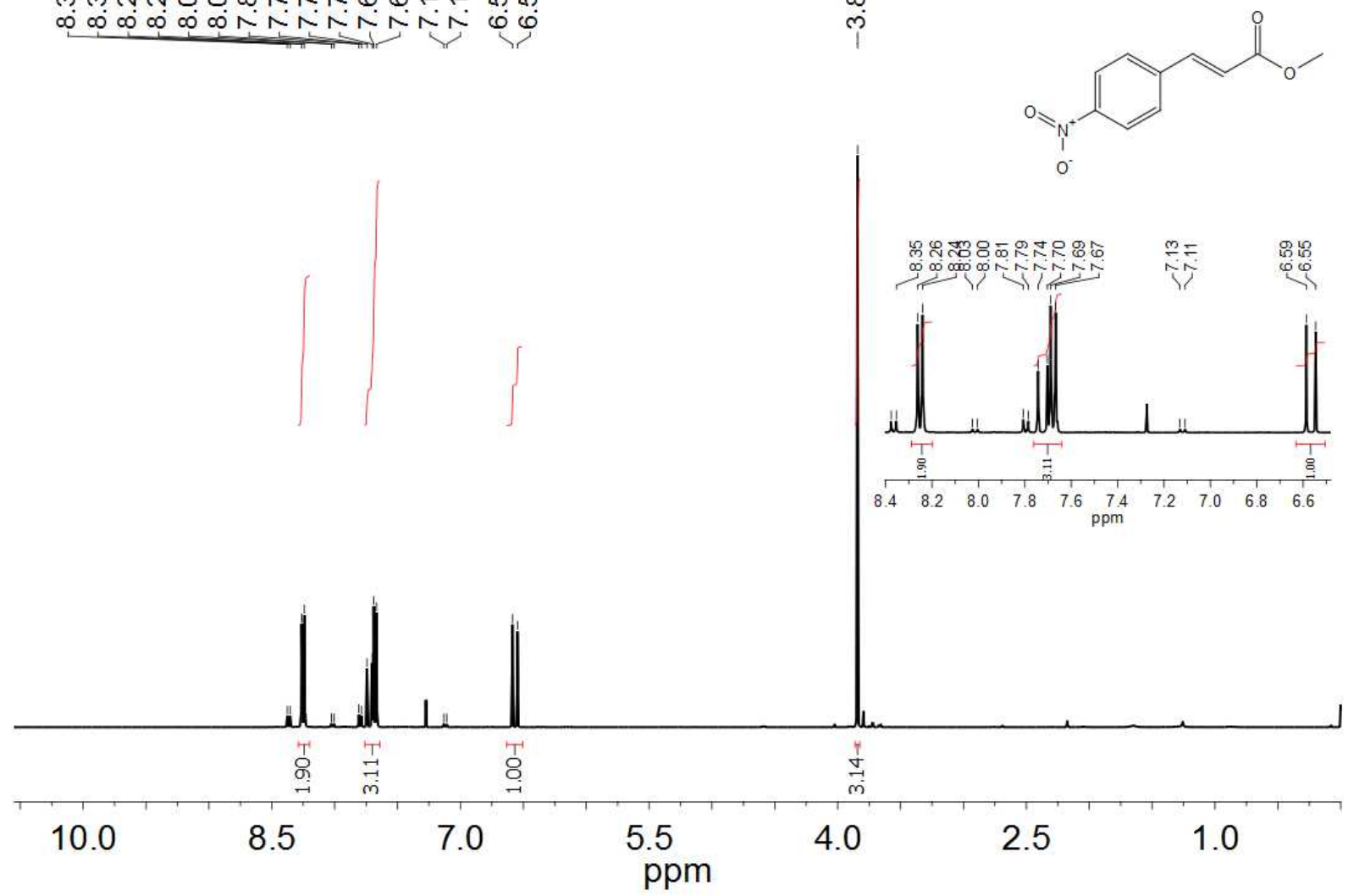

Figure S20. ${ }^{1} \mathrm{H}$ NMR of (E)-methyl 3-(4-nitrophenyl)acrylate (11d). 


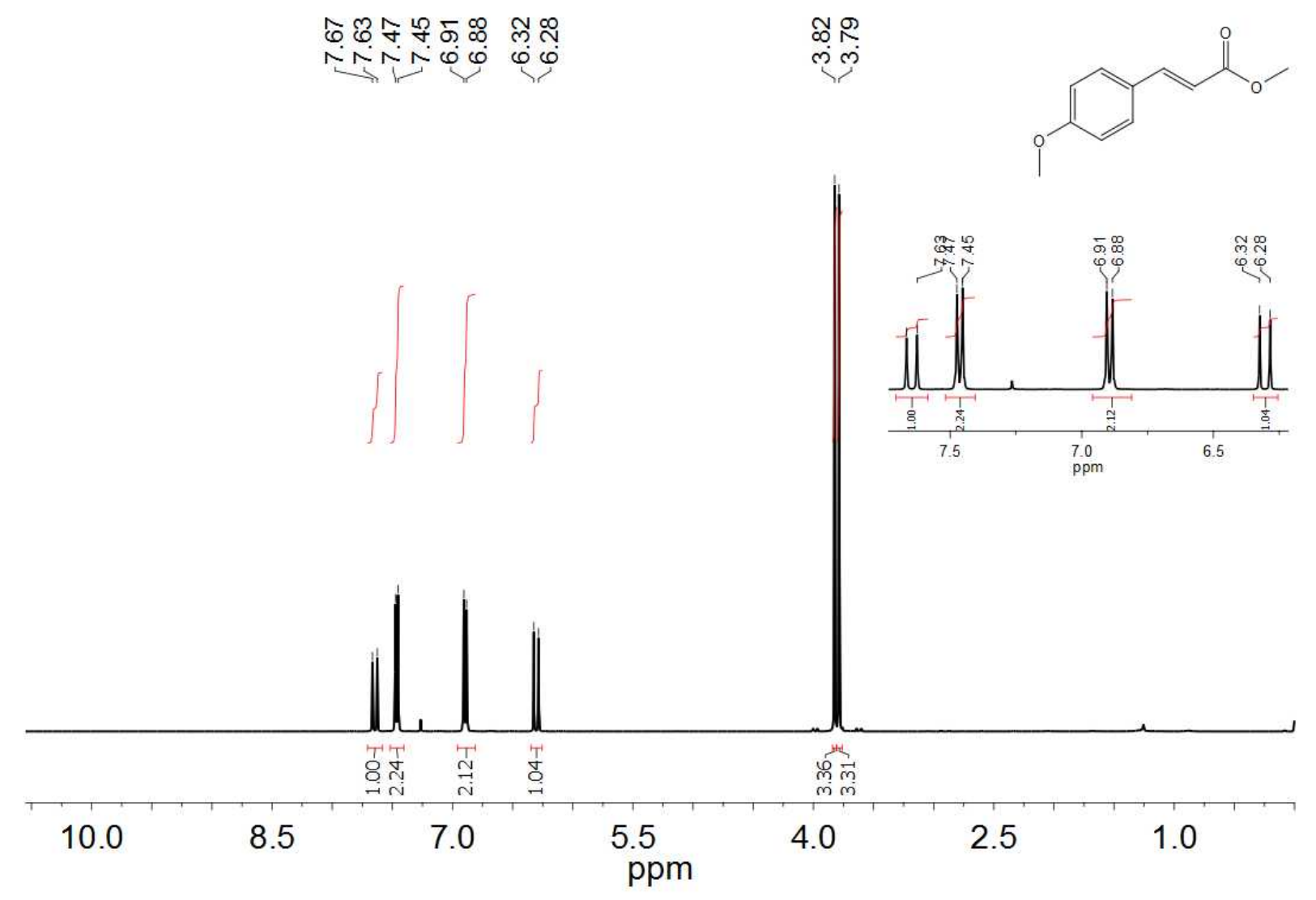

Figure S21. ${ }^{1}$ H NMR of (E)-methyl 3-(4-methoxyphenyl)acrylate (11e).

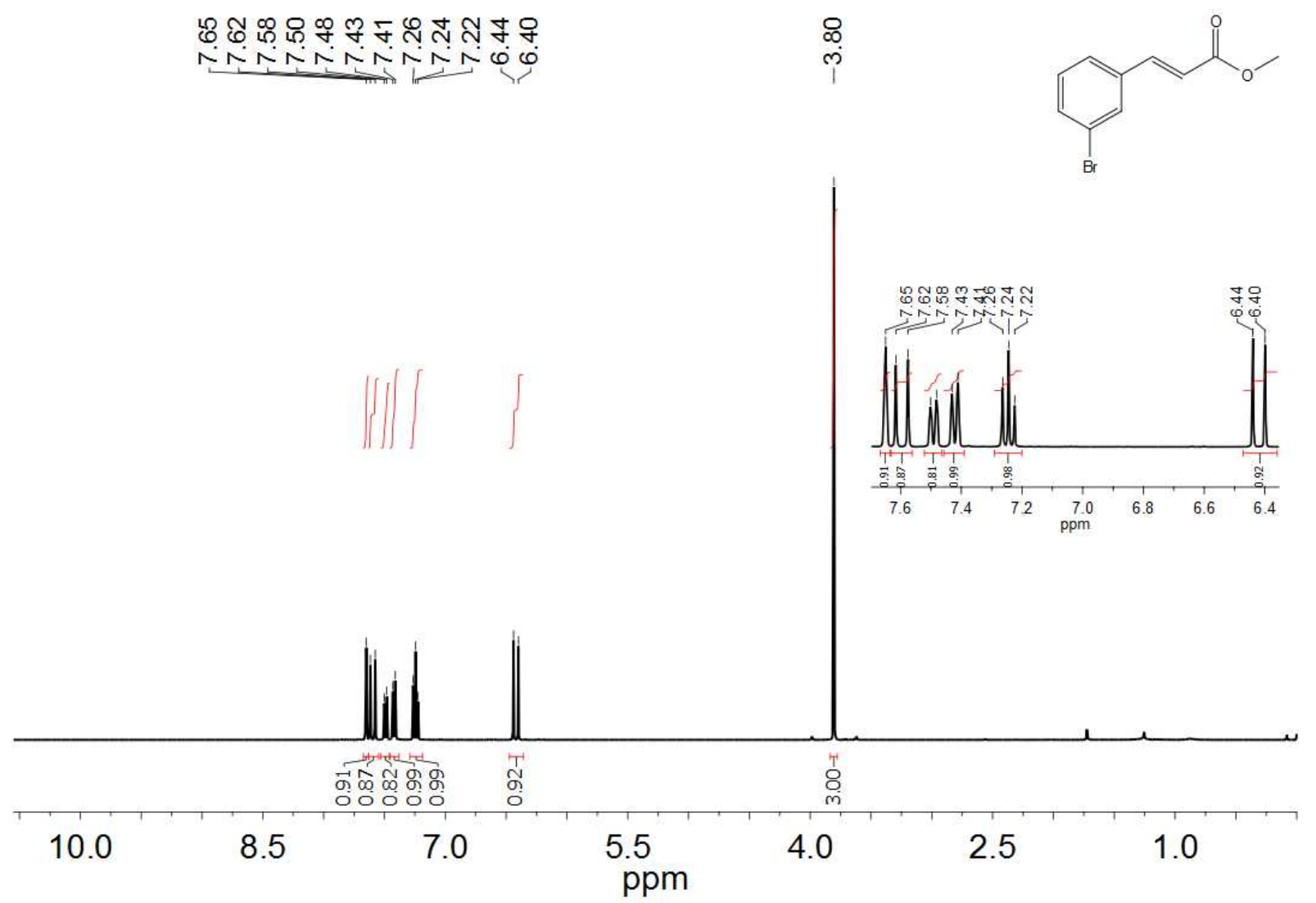

Figure S22. ${ }^{1}$ H NMR of (E)-methyl 3-(3-bromophenyl)acrylate (11f). 